\title{
Policy Brief: Penelusuran Ancaman Kasus TB pada Petugas Kesehatan di Indonesia
}

[Riana Dian Anggraini /Eka Putri Rahayu/Arqu Aminuzzab]

[Gadjah Mada University]

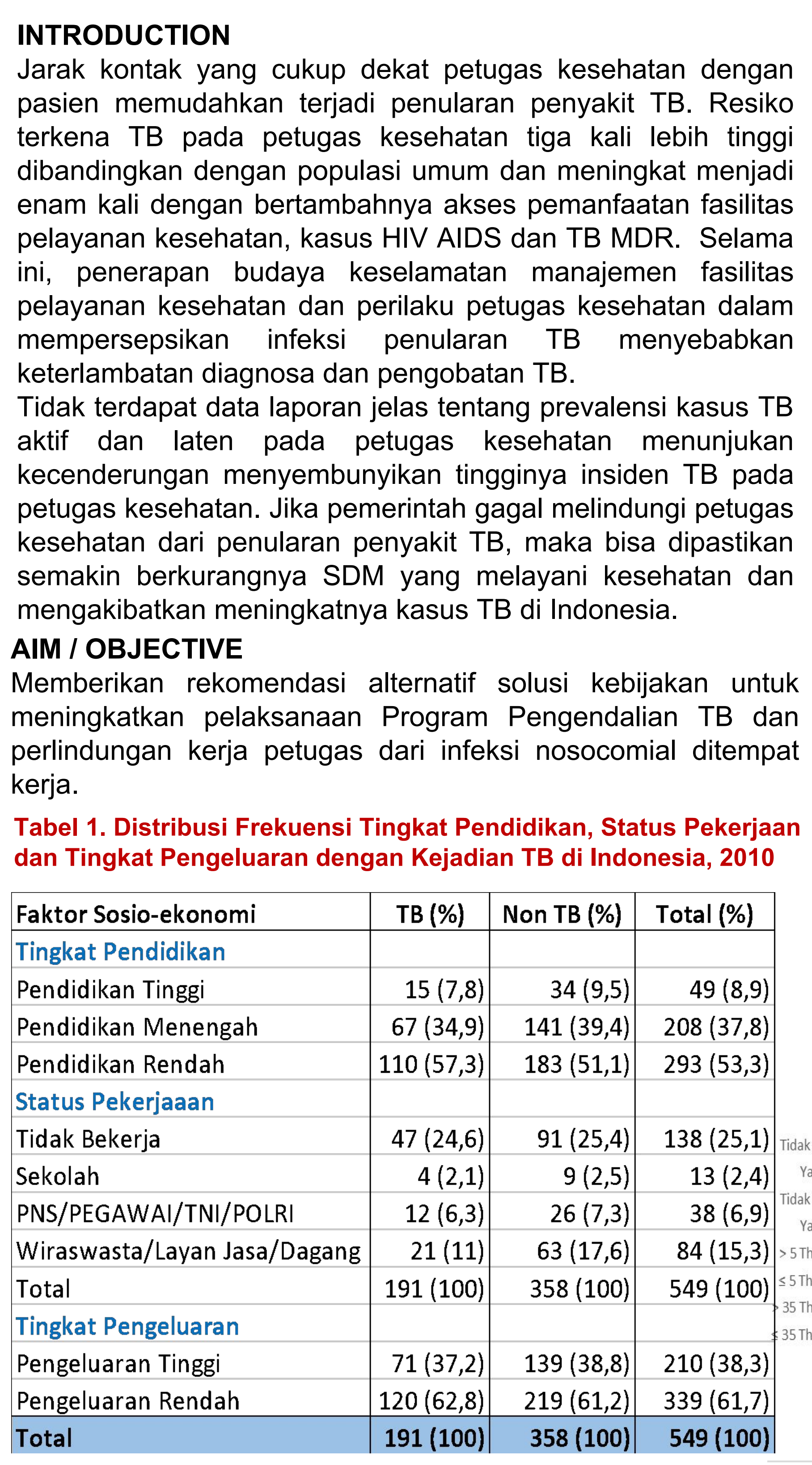

Tabel 2. Distribusi frekuensi umur dengan Kejadian TB di Indonesia

\begin{tabular}{|c|c|c|c|}
\hline Faktor Umur & TB (\%) & Non TB (\%) & Total $(\%)$ \\
\hline $15-34$ tahun & $72(37,7)$ & $127(35,5)$ & $199(36$ \\
\hline $35-54$ tahun & $93(48,7)$ & $151(42,2)$ & $224(4$ \\
\hline 55-74 tahun & $22(11,5)$ & $70(19,6)$ & $92(1$ \\
\hline$>74$ tahun & $4(2,1)$ & $10(2,8)$ & 14( \\
\hline Total & $191(100)$ & $8(100)$ & $549(10$ \\
\hline
\end{tabular}

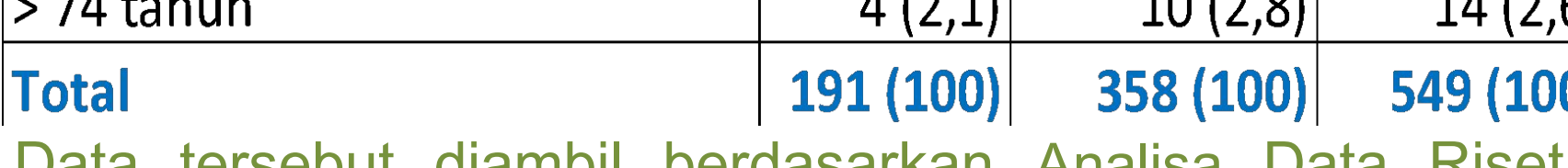
Data tersebut diambil berda

\section{METHODS}

Metode yang digunakan dalam penulisan policy brief adalah metode pustaka. Penulis melakukan penelusuran pustaka yang terkait dengan angka kejadian dan faktor resiko TB pada petugas kesehatan serta kebijakan-kebijakan yang dikeluarkan oleh pemerintah yang terkait dengan kebijakan proteksi tenaga kerja terhadap infeksi TB di fasilitas pelayanan kesehatan. Dari bahan-bahan pustaka yang telah terkumpul selanjutnya dilakukan analisis dan sistesis untuk membangun suatu alternatif solusi yang hendak ditawarkan dalam penemuan dan penanganan kasus TB pada petugas kesehatan sebagai populasi berisiko. Grafik1.2. Hasil Penelitian

Berdasarkan penelitian Prevalens TB Laten Pada Petugas
Kesehatan Di RSUP H. Adam Malik Medan pada Tahun 2010 Hasil Tes Tuberkulin

Grafik2. Prvalensi TB laten berdasarkan tempat keria

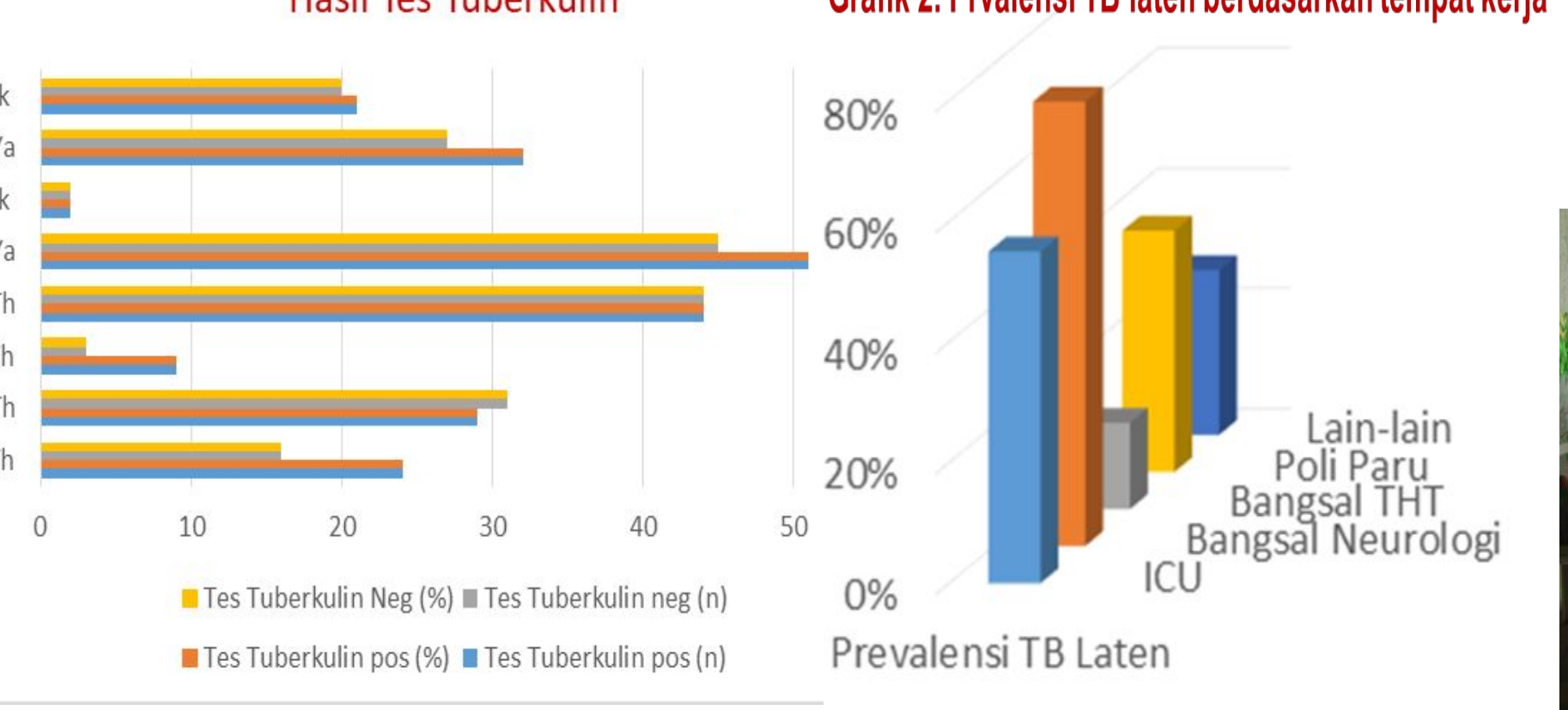

RESULTS

Bagaimana jumlah kasus TB pada petugas kesehatan? Sampai saat ini belum ada data laporan maupu penelitian terkait prevalensi infeksi TB aktif maupun TB laten pada petugas kesehatan. Penelitian systematic review yang dilakukan oleh Rajnish Joshi dkk menyatakan bahwa rata-rata prevalensi TB laten petugas kesehatan $54 \%$ (berkisar antara $33 \%$ sampai $79 \%$ ). Diperkirakan insiden penyakit TB pada petugas kesehatan antara 69 sampai 5780 per 100.000 pe tahun. Resiko petugas kesehatan terinfeksi TB lebih besar dibandingkan populasi umum antara 25 sampa 5.361 per 100.000 per tahun. Peningkatan resiko dikaitkan dengan lokasi kerja tertentu (labolatorium ruang rawat inap TB, UGD, poli spesialis penyakit dalam) dan kategori pekerjaan (radiographer, tenaga pendaftaran, perawat, dokter, tenaga kebersihan, analis laboratorium).

Penelitian yang dilakukan di RSUP H Adam Malik Medan menunjukkan bahwa dari sampel 100 orang yang dilakukan tes tuberculin didapatkan 53 orang has tes positif dan 47 orang hasil tes negatif. Prevalensi TB laten pada petugas kesehatan adalah $53 \%$. Fakto resiko terjadinya tes reaksi tuberculin pos 5 . Fakto $>35$ tahun lama bekeria dan adanya kontak dengan penderita TB. Tingginya prevalensi TB laten petugas kesehatan dipengaruhi on besarnya beban infeksi TB pada masyarakat dan difasilitas pelayanan kese paca masyarakat dan difasiltas pelayanan kesehatan dirawat.
.

Gambar 1. : Kondisi Pelayanan Petugas Kesehatan

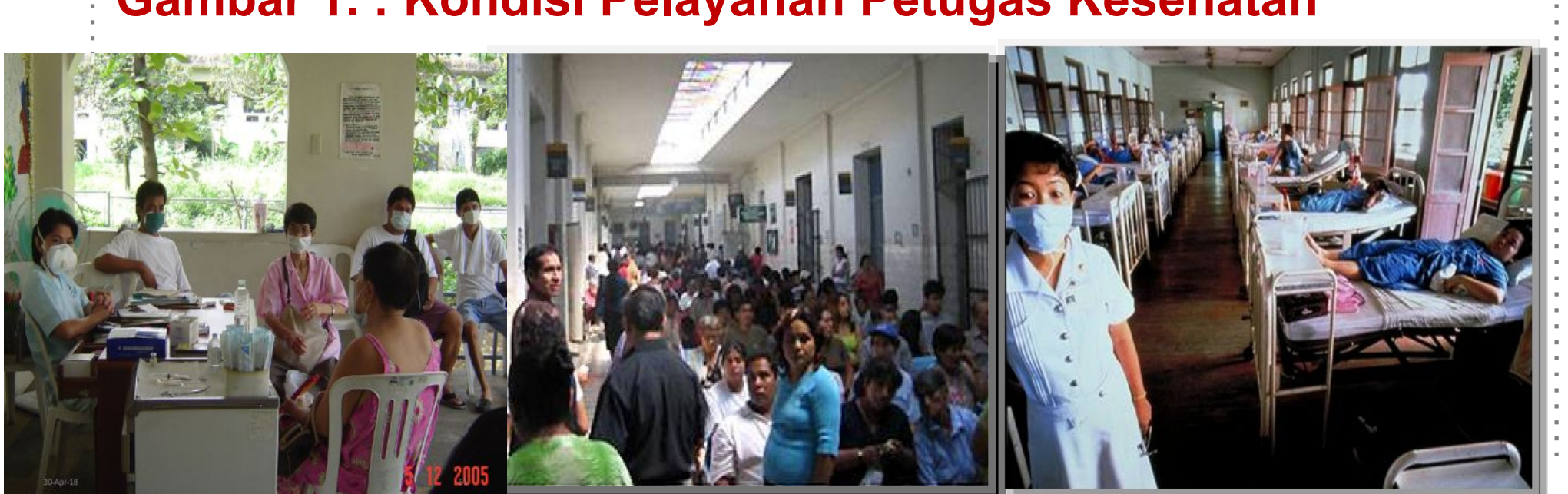

\section{CONCLUSIONS}

TB merupakan masalah kesehatan akibat kerja yang signifikan pada petugas kesehatan. Petugas kesehatan merupakan populasi beresiko terinfeksi TB tetapi tidak ada data resmi terkait kasus TB pada petugas kesehatan. Dalam mengurangi paparan TB di fasilitas pelayanan kesehatan perlu dibangun sistem pengendalian infeksi untuk memastikan kesehatan petugas kesehatan dan mengurangi penularan TB $d$ fasilitas pelayanan kesehatan. Kebijakan yang ada belum mengatur dengan jelas tentang TB akibat kerja pada petugas kesehatan, sanksi hukum, pengawasan berkelanjutan PPI di fasilitas pelayanan kesehatan kompensasi dan pelaporan kasus TB pada petugas kesehatan

Rekomendasi untuk Kementerian Kesehatan dan Dinas Kesehatan perlu memperkuat kebijakan dan pengembangan strategi berbasis bukti laporan data prevalensi dan insiden kasus TB petugas kesehatan Manajemen faskes dan petugas kesehatan wajib melaksanakan PPI sesuai standart, melakukan pemeriksaan skrining TB dan HIV serta mengutamakan budaya keselamatan dalam bekerja.

BIBLIOGRAPHY

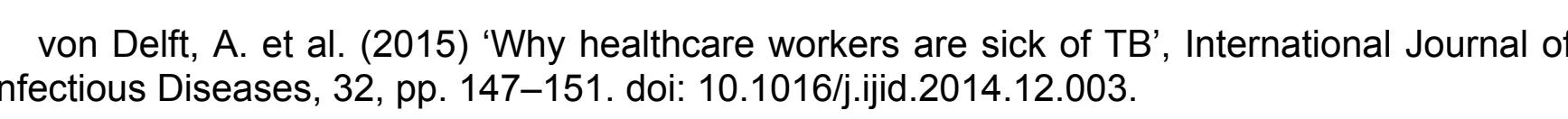

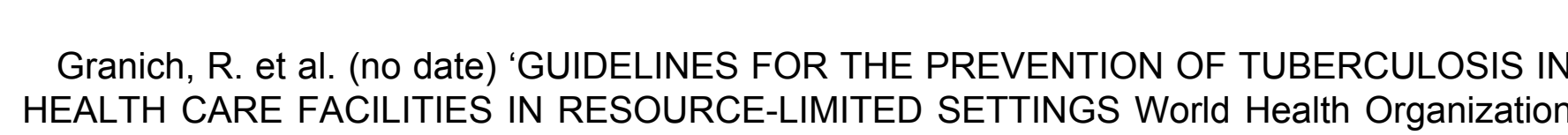

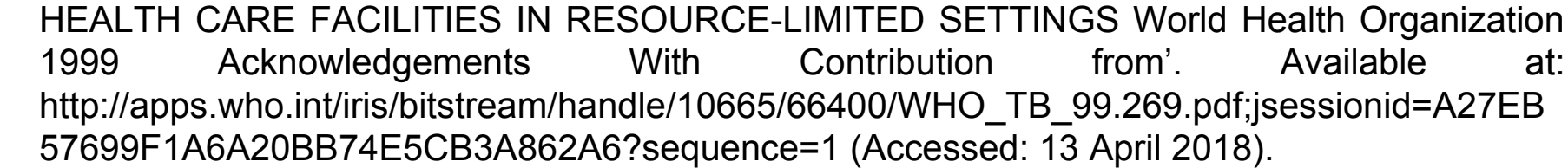
Indonesia. Badan Penelitian dan Pengembangan Kesehatan (no date) Buletin penelitian
Avistem
Avalable

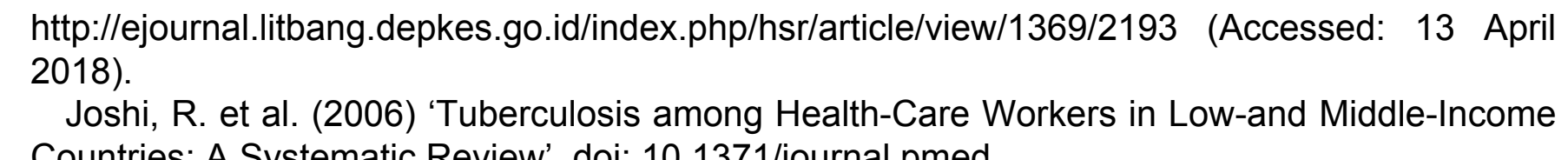

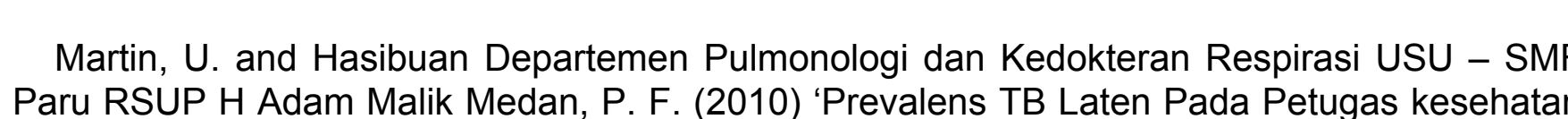

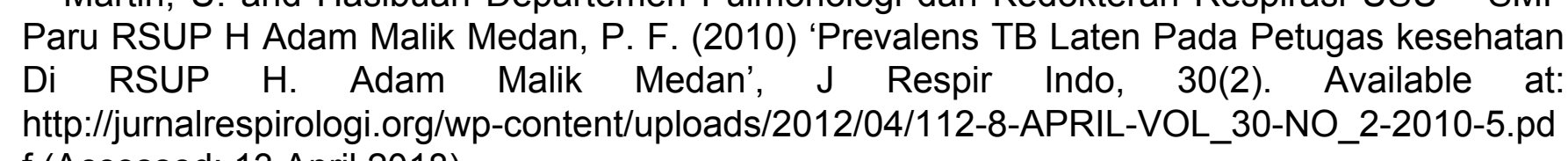

